\title{
LETTER
}

doi:10.1017/\$1041610205002875

\section{Reflections on changes in defining testamentary capacity}

Old age psychiatrists are often called upon to give expert evidence in challenges of testamentary capacity. The nineteenth-century English case, Banks v. Goodfellow (1870) remains the hallmark case for defining the criteria for testamentary capacity in Australia and other Common Law countries. However, a need to go beyond the traditional Banks and Goodfellow criteria for defining testamentary capacity (i.e. (i) understanding of the nature of a will; (ii) knowledge of the nature and extent of one's assets; (iii) being able to recall and understand the claims of potential heirs; (iv) being free of delusions or hallucinations that influence one's testamentary decisions) has been identified recently in the international literature (Shulman et al., 2005). Recent court rulings in Australia which have acknowledged the differences between the nineteenth-century context and today are therefore of international interest, as are recently adapted guidelines for clinicians asked to assess capacity.

Importantly, Banks and Goodfellow was based on a case of psychosis, which these days is far outnumbered by dementia as the basis for will challenges (Shulman et al., 2005). Further, the expectations of testators in 19th century England and our understanding of psychopathology and cognition have obviously evolved. This has had most impact on the criteria for knowledge of the nature and extent of assets (the threshold for which has been lowered) and for recalling and understanding the claims of potential heirs (the threshold for which has risen).

With regards to the former, a recent Australian case (Kerr v. Badran, 2004) has openly acknowledged the differences between 1870 and today:

In dealing with the Banks v. Goodfellow test it is, I think, necessary to bear in mind the differences between life in 1870 and life in 1995. The average expectation of life for reasonably affluent people in England in 1870 was probably less than 60 years and for others less well-off under 50 years: the average life expectancy of males in Australia in 1995 was 75 years. Younger people can be expected to have a more accurate understanding of the value of money than older people...

In England in 1870, if you had property it was likely to be lands or bonds or shares in railway companies or government-backed enterprises. Investment in ordinary companies was far less common than now. Older people living today may well be aware that they own substantial shareholdings or substantial real estate, but yet may not have an 
accurate understanding of the value of those assets, nor for that matter, the addresses of the real estate or the particular shareholdings which they have. Many people have handed over management of share portfolios and even real estate investments to advisors...

I think that this needs to be kept in mind in 2004 when the requirement of knowing "the extent" of the estate is considered

On the other hand, a more complex appraisal of the claims of beneficiaries is now required. Based on an often-cited Australian case (Read v. Carmody, 1998), a more complex definition of capacity has been modified for clinicians (Bennett and Hallen, 2004):

i. Is it likely that any impairment was present which may have compromised the deceased's capacity with respect to an awareness and appreciation of the significance of the act of making a will?

ii. Is it likely that any impairment was present which may have compromised the deceased's capacity with respect to an awareness in general terms of the nature and extent of his estate?

iii. Is it likely that any impairment was present which may have compromised the deceased's capacity with respect to an awareness of those who might reasonably have been thought to have a claim on the deceased's testamentary bounty?

iv. Is it likely that any impairment was present which may have compromised the deceased's capacity with respect to ability to identify, evaluate and discriminate between the respective strengths of the claims of such persons?

v. Is it likely that any disorder of mind such as delusions and hallucinations which would influence the deceased's awareness of facts or reasoning and decision-making ability specifically with regard to the above four capacities?

Personal experience as an expert witness in over 70 will challenges has suggested that while some people with dementia may not be aware of those who might have a claim on their bounty, most wills are challenged on the basis of the testator's capacity to identify, evaluate and discriminate between the respective strengths of the claims of their potential beneficiaries. This task is perhaps the most complex for the testator. Accordingly, the author's assessment of this crucial part of capacity is usually based on the examination of the following pieces of evidence:

(i) the history of disposal or the will-making pattern. Previous wills, which may demonstrate an enduring and stable pattern of bequests, reflect views held by the testator prior to any significant deterioration of mental 
state. Suspicion as to incapacity is aroused when a testator revokes prior wills and executes entirely different dispositions during a period of mental enfeeblement

(ii) the terms of the will (as inference of capacity may be derived from the will itself). Where the will is inofficious, where no provision, or an apparently inadequate or unfair provision, is made for those who ought to be the objects of the testator's bounty, then fuller and clearer evidence of capacity is required

(iii) the testator's appraisal of his potential heirs. Many of the neuropsychological deficits typically associated with common forms of dementia may influence the appraisal of relationships with intimate and diffuse others. Firstly, executive dysfunction, which is an early feature of vascular and frontotemporal dementia (Kertesz and Clydesdale, 1994), and often Alzheimer's disease (Ready et al., 2003), will adversely affect judgement and reasoning. Deficits in working memory may render a person with dementia unable to appraise their relationships in the context of the past and present simultaneously. This may render them prone to making shallow, superficial and impulsive judgements of people or situations (Masterman and Cummings, 1997) and vulnerable to the influence of those with whom they are in frequent contact.

Secondly, impairment in autobiographical memory may make it difficult to retrieve meaningful, relationship-focused events and feelings from the past (Kazui et al., 2000). Thirdly, personality change, such as apathy and passivity, render people with dementia vulnerable to the influence of others' opinions. Finally, this is often complicated further by suspiciousness, paranoid ideation and sometimes delusions, which may seed doubt in the person with dementia's mind about the intent of previously trusted family members or friends.

It is not surprising that in our recent study examining 50 cases of family conflict presented to the Guardianship Tribunal of New South Wales (NSW), we found that the person with dementia (usually mild to moderate) was most often involved in the conflict or in alliance with one or other of the family camps (Peisah et al., 2005). Thus, to ensure ill-feeling towards family members is not contaminated by dementia, in situations involving complex and conflictual issues amongst potential beneficiaries, the testator should: show an awareness of these issues and provide the rationale for the disposition, or as is most often the case, the change in the disposition... (Shulman et al., p. 68)

Clearly, this approach to the assessment of capacity is far more complex than previously recommended (Peisah and Brodaty, 1994), but in keeping with the state of the art of capacity assessment in general, where there has long-been insistence on more than "parrot-like" repetition of knowledge in decision-making (Freedman et al., 1991). 
Our experience in dealing with the issue of testamentary capacity in Australia is clearly of relevance to other countries. Times are changing for medico-legal experts in this field, as assessments are becoming more complex, challenging and of course, more interesting.

\section{Acknowledgements}

The author thanks Hayley Bennett for her comments on drafts of this paper.

\section{References}

Banks v. Goodfellow. 1870.LR.5.Q.B. 549.

Bennett, H. P. and Hallen, P. (2004). Dementia, cognition and testamentary capacity. Brain Impairment, 5, 69-70.

Freedman, M., Stuss, D. T. and Gordon, M. (1991). Assessment of competency: the role of neurobehavioural deficits. Annals of Internal Medicine, 115, 203-208.

Kazui, H., Hashimoto, M., Hirono, N. et al. (2000). A study of remote memory impairment in Alzheimer's disease by using the family-line test. Dementia and Geriatric Cognitive Disorders, $11,53-58$.

Kerr v. Badran (2004). NSWSC 735 (per Windeyer J) at 49.

Kertesz, A. and Clydesdale, S. (1994). Neuropsychological deficits in vascular dementia vs Alzheimer's disease. Archives of Neurology, 51, 1226-1231.

Masterman, D. L. and Cummings, J. L. (1997). Frontal-subcortical circuits: the anatomic basis of executive, social and motivated behaviors. fournal of Psychopharmacology, 11, 107-114.

Mendez, M. F. and Cummings, J. L. (2003). Dementia: a clinical approach (3rd ed). Philadelphia: Butterworth Heinemann.

Peisah, C., Brodaty, H. and Quadrio, C. (2005). Family conflict in dementia: prodigal sons and black sheep. (unpublished data, submitted)

Peisah, C. and Brodaty, H. (1994). Dementia and the will-making process. Medical fournal of Australia, 161, 381-384.

Read v. Carmody NSWCA, 23 July 1998, unreported.

Ready, R. E., Ott, B. R., Grace, J. et al. (2003). Apathy and executive dysfunction in mild cognitive impairment and Alzheimer disease. American fournal of Geriatric Psychiatry, 11, 222-228.

Shulman, K. I., Cohen, C. A. and Hull, I. (2005). Psychiatric issues in retrospective challenges of testamentary capacity. International fournal of Geriatric Psychiatry, 20, 3-69.

Carmelle Peisah, MD

Academic Department for Old Age Psychiatry, Prince of Wales Hospital, University of New South Wales, Sydney, Australia

Email: cpeisah62@optusnet.com.au 